Technische

Universität

Berlin

Jenny Rieck, Lina Taube, Frank Behrendt

\title{
Feasibility analysis of a heat pump powered by wind turbines and PV-applications for detached houses in Germany
}

Open Access via institutional repository of Technische Universität Berlin

\section{Document type}

Journal article | Accepted version

(i. e. final author-created version that incorporates referee comments and is the version accepted for publication; also known as: Author's Accepted Manuscript (AAM), Final Draft, Postprint)

This version is available at

https://doi.org/10.14279/depositonce-12170

Citation details

Rieck, J., Taube, L., Behrendt, F. (2020). Feasibility analysis of a heat pump powered by wind turbines and PVApplications for detached houses in Germany. Renewable Energy, 162, 1104-1112.

https://doi.org/10.1016/j.renene.2020.07.011

Terms of use

This work is protected by copyright and/or related rights. You are free to use this work in any way permitted by the copyright and related rights legislation that applies to your usage. For other uses, you must obtain permission from the rights-holder(s). 


\title{
Feasibility analysis of a heat pump powered by wind turbines and PV - applications for detached houses in Germany
}

\author{
Jenny Rieck*a ${ }^{*}$ Lina Taube ${ }^{\mathrm{b}}$, Frank Behrendt ${ }^{\mathrm{b}}$ \\ ${ }^{a} T U$ Berlin, Department of Energy Process Engineering and Conversion Technologies of Renewable Energies Berlin, \\ Germany, jenny.rieck@tu-berlin.de \\ ${ }^{b}$ TU Berlin, Department of Energy Process Engineering and Conversion Technologies of Renewable Energies Berlin, \\ Germany
}

\begin{abstract}
In this study an intelligent energy supply system is developed. Energy is obtained by wind or solar radiation and stored to cover the electricity and heat demand of a detached house in Germany. For this a heat pump and a storage tank is used. The simulation shows strategies to integrate renewable energies in different regions of Germany while diminishing the need to turn off a wind turbine or feed energy to the grid. For this, the energy consumption in a single house is modelled. Different wind turbines and PV systems are introduced as an energy source. The profitability of these systems is calculated and compared to conventional systems with gas or oil. The analysis shows that at the moment small wind turbines are a feasible option for cover the energy demand under the given conditions. On the other hand, currently PV plants are not suitable for the heat demand coverage as the specific costs outgo the ones for conventional systems. Further research is necessary to look at different case scenarios, taking into account future climate developments.
\end{abstract}

Keywords: Integrated Energy, Micro Energy Systems, Space Heating, Sector-coupling, Small wind turbines, Photovoltaic

\section{Introduction}

The Climate Protection Act by the German Federal Government aims to reduce $\mathrm{CO}_{2}$ emissions by $55 \%$ in 2050 . The emissions by the energy industry and the building sector even should be decreased by more than $60 \%$ [1]. This is only possible by increasing the share of renewable energies. While their fraction in the power sector was $36 \%$ in 2017, for the heating sector the share was only by $13.9 \%$ [2]. Therefore the integration of renewable energies in this sector is of particular importance. This can be achieved by increased usage of biomass but also by efficient power-based heating devices, especially for private households. As one focus of the renewable energy strategy of the German Government lies on the expansion of wind and PV power plants, coupling the power and heating sector is consequential. While decentralised concepts for PV plants are already quite common (e. g. on roofs [3]), using small wind turbines for energy supply of single households is not. For both technologies there is the challenge of high volatility, which means that energy demand and generation are unequally distributed. This especially applies for decentralised plants, as it is not possible to balance this effect the same way as in larger Preprint submitted to Renewable Energy

May 29, 2020 
power distribution grids.

One way to counteract the volatility is the integration of an energy storage system [4], another is to shift demand from peak hours to offpeak hours, a strategy known as demand side management [5]. A further option is to feed excess electricity to the grid and get rewarded for it. In times the electricity generated decentrally does not meet the demand, electricity from the grid can be used. However, currently the feed-in tariffs for wind power plants up to $750 \mathrm{~kW}$ are 4.63 cents $/ \mathrm{kWh}$, and 11.51 cents $/ \mathrm{kWh}$ for PV plants up to $10 \mathrm{~kW}$ peak [6]. As the electricity price is around 29.87 cents/ $\mathrm{kWh}$ at the moment [7], it is more attractive to use the electricity oneself.

As demand side management is not as easily achieved on a decentralised level storage is the main option to react to renewable energy volatility. While battery storages become more common, they are still costly, decreasing the economic efficiency of renewable energy systems. Heat production from electricity and storage of this heat can be an alternative. However, there are some challenges connected to this too that need to be analysed: peaks in electrity generation by PV and those of heat demand are anticyclical and seasonal heat storage is not economically viable for private households yet [8]. Space for decentralised renewable energy plants is limited, especially for PV roof plants. Investment costs for the necessary appliances can make heat supply economically unfavourable. This especially applies as the costs for conventional heat supply by fossil fuels (oil, gas) are already lower by more than a third compared to grid electrictiy. Electricity demand by other consumers (household appliances etc.) might compete with the heat demand. Finally, the mean building age is 28 years in Germany, whichs means that good thermal isolation does not exist comprehensively [9]. Overall, it needs to be carefully analysed, in which cases a system restructure towards heat generation from electricity is sensible.

First, the examined house structure needs to be defined, for which the decentralised energy supply is supposed be realised. It can be provided for a whole quarters, but also solely for a single building. This building can be a tower, an apartment house or a single family house. The installation of wind power plants are more suitable in rural areas as wind flow is not as restrained as in cities. In these rural areas detached single family houses are very common [10]. Therefore these building type is especially interesting for studying energy supply by wind and PV. Additionally, heat and warm water demand from a single-family house consist of $84 \%$ of the total energy demand [11]. Therefore, the implementation of a climate friendly heat supply is of special importance.

Several studies have been conducted on the integration of renewable energies in detached houses. In [12] the focus was on benefits of utilising on-site and off-site renewable energy sources for a single family detached house. Bracke et al. [16] researched the prerequisites for a self-sufficient energy supply and the necessary technologies for it. The assessment of the modifications in the German Combined Heat and Power (CHP) Act in 2016 with respect to technical, economic and ecological aspects is given by [17]. In [18] the requirements and consequences of an extensive heat transition towards a heat demand coverage based on renewable energies was analysed. Indicators concerning technical and economic aspects as well as energy and climate protection policy were identified and presented.

Additionally, small wind power plants up to $10 \mathrm{~kW}$ for decentralised, household-specific energy supply is not researched in great detail. Ghaith et al. studied the potential for household 
wind power plants in Oklahoma [13]. However, the US net metering system enables a load shift, making it unnecessary to implement storage options. This concept is not available in other countries, like Germany. Heat generation using electricity was not considered. Predescu looked at the economics of small wind power plants for residential consumers without taking into account consumer behaviour [14]. Grieser et al. compared different regions in Germany in regards to their potential to install small wind turbines for household electricity supply. They found positive net present values for some of these regions but stated that urban areas with higher density affect the results negatively. They did not consider sector coupling, but rather used battery storage systems [15].

It becomes clear that there are studies that look at the energy supply by renewable energies for single houses and there are those concerend with small wind power plants. However, until now there is hardly anything to find that compares the energy demand of houses of different conditions with different renewable energy supply options taking into account sector coupling as a mean to consider the volatility of these energy sources. This study tries to fill this void by looking at decentralised electricity production and electricity consumption for power and heat in detached houses in different regions in Germany. Chosing a detached area is compliance with the study by Grieser et al, expanding their scope by also considering PV as renewable energy source and heat as additional consumption. The focus lies on buildings built at the begin of the 21 century that have a higher heat demand compared to relatively new constructed buildings. At the same time it can be assumed that they can be representative of older but modernised buildings. Thereby, the results of the study have a greater significance for the integration of dezentralised PV and wind power plants for heating purposes in Germany and countries with similar building and climate structure.

For the introduced model, a small wind turbine or a PV plant should provide the energy for electricity and heat demand of a detached house parallel to the existing grid. The possibility of establishing this kind of plant besides an already existing home supply system is investigated to design a renewable energy system for local applications. Since demand and energy generation can occur at different periods, an intelligent system is needed to distribute the energy in time. The overall objective of this study is the development of an intelligent energy supply system where the energy is obtained by wind or solar radiation and stored in a heat storage tank if necessary. For this a heat pump is used. The goal is to use the whole energy potential and diminish the need to turn off the turbine or to feed energy to the grid. The study aims to reveal the conditions under which the most efficient power output and profitability of the system occurs.

\section{Methodology}

Following, the methodology of all calculations is presented. A so called test reference year given by Germany's National Meteorological Service is used as basis for the calculation of wind speed and solar radiation. In this case, test reference year means that the data is synthesised of 20 years (1988 - 2007) of measured weather data. It includes hourly data for 365 days and 15 regions in Germany, concerning among others wind speed and direct and diffuse solar radiation [19]. Several data sources are used to calculate the generated electricity for every hour of the year. For the wind power plant system, micro and mini wind turbines up to $10 \mathrm{~kW}$ are considered. Micro wind turbines have a nominal power smaller than $5 \mathrm{~kW}$, mini wind turbines operate in a range of $5-30 \mathrm{~kW}$. For the PV system modelling, plants with nominal power between 2.44 and 
$9.9 \mathrm{~kW}$ are taken into account. Table 1 shows all used wind turbines and PV plants with the nominal power and their respective data source.

Table 1: Wind turbines and PV plants

\begin{tabular}{|c|c|c|c|c|c|}
\hline Wind turbines & $\begin{array}{c}\text { nominal } \\
\text { power } \mathrm{kW}\end{array}$ & $\begin{array}{c}\text { data } \\
\text { source }\end{array}$ & PV plants & $\begin{array}{c}\text { nominal } \\
\text { power } \mathrm{kW}\end{array}$ & $\begin{array}{c}\text { data } \\
\text { source }\end{array}$ \\
\hline SW Skystream 3.7 & 1.9 & 20 & Aleo Solar S19 HE Tec & 2.44 & [22] \\
\hline Exmork HM $3.2-2000$ & 2 & 20 & Viessmann Vitovolt 300 Typ P275 AB & 3.3 & {$[23$} \\
\hline Skyline sl - 30 & 3 & 21 & Viessmann Vitovolt 300 Typ P275 AB & 4.4 & $\mid 24$ \\
\hline Exmork HM $4.5-3000$ & 3 & 20 & Aleo Solar X59 HE Tec & 5.58 & $\mid 25$ \\
\hline Uge $-4 \mathrm{~K}$ & 4 & 21 & LG325N1K-V5 NeON 2 Black Cello & 5.85 & 26 \\
\hline Cyclone $4.8 \mathrm{KW}$ & 4.8 & 20 & BenQ Solar SunForte PM096B00 & 6 & 27 \\
\hline Inclin $6000 \mathrm{Neo}$ & 6 & 20 & LG320N1K-V5 NeON 2 Black Cello & 6.72 & $\overrightarrow{28}$ \\
\hline \multirow[t]{2}{*}{ Fortis Alize } & 10 & 21 & Aleo Solar X79 & 8.37 & 29 \\
\hline & & & LG330N1C-A5 NeON 2 & 9.9 & [30 \\
\hline
\end{tabular}

\subsection{Calculation of energy demands}

The calculation of the daily heat demand is different from the other daily demand calculations, as the heat consumption depends largely on the condition of the building. Whereas the electricity and the hot water demand vary mainly with the behaviour of the consumer, so for these two demands mean values are used. Both methodologies are explained in this paragraph, starting with the heat demad calculation. For that, data given by the EU project TABULAR [31] is used, which analysed the heat demand for a building portfolio in 13 different European countries. The full building portfolio is represented by ten different building types. These types can be distinguish by the construction year and by the designated use of the building. The project analysed various houses for very different usage, but for this study only the characteristic energy values for detached houses are needed. The calculation of this characteristic energy values was done according to European standards, such as the EN ISO 13790 for the calculation of energy use for space heating and cooling and the EN 15316 for the calculation of system energy requirements. The heat demand per square meter and the living space that needs to be heated is considered to calculate the heat demand. By multiplying these two values with each other, the heat demand of the whole house for a year is obtained. Table 2 shows the overall heat demand, the heat demand per square meter and the heated living space for different building ages. In this study only buildings from 2002 to 2009 are modelled. The assumption is that modernisation efforts in older buildings will decrease their heat demand in future. Therefore, the focus lies on the newest age group as reference for older, renovated buildings.

Table 2: Characteristic energy values for detached houses [31

\begin{tabular}{cccc}
\hline Building year & heat demand $\frac{\mathrm{kW}}{\mathrm{m}^{2} a}$ & heated living space $\mathrm{m}^{2}$ & heat demand $\frac{\mathrm{kW}}{\mathrm{a}}$ \\
\hline $1958-1968$ & 211.1 & 242.0 & 51086.2 \\
$1969-1978$ & 232.7 & 157.5 & 36650.3 \\
$1979-1983$ & 149.3 & 196.0 & 29262.8 \\
$1984-1994$ & 177.9 & 136.6 & 24301.1 \\
$1995-2001$ & 134.9 & 110.8 & 14946.9 \\
$2002-2009$ & 101.3 & 133.2 & 13493.2 \\
\hline
\end{tabular}


The respective heat demand needs to be split to receive the daily heat demand. This is not done by just dividing the value by 365 days, as the heat demand in the winter time is much higher than the heat demand in spring. Instead the method of reference demand profiles introduced by [32] is employed. First obtained is the so called customer value $C V$, again a yearly demand value. The calculated customer value is a side specific value, whereas the values in table 2 are generalised demand values.

$$
C V=\frac{Q_{N}}{\sum_{i}^{N} h(v)}
$$

The heat demand of one year $Q_{N}$, given in table 2 , is divided by the sum of all temperature regression functions $h$ of one year. The temperature regression function is influenced by the mean temperature $v$. Hence all buildings are able to store heat it is necessary to consider this ability in the calculation. In the method of reference demand profiles this is done by calculating a mean temperature considering four serial days. So if the mean temperature of a given day is needed, the temperature value of this given day $T_{x}$ and of the three days before are considered.

$$
v=\frac{T_{x}+0.5 \cdot T_{x-1}+0.25 \cdot T_{x-2}+0.125 \cdot T_{x-3}}{1+0.5+0.25+0.125}
$$

In addition the temperature regression function $h$ is specified by a set of coefficients, so that the outcome is only valid for a given wind condition, a designated use and a specific age of a building. The coefficients $\left(s_{A}, s_{B}, s_{C}\right.$ and $\left.s_{D}\right)$ are called Sigmoid parameters and are given in [32].

$$
h=\frac{s_{A}}{1+\left(\frac{s_{B}}{v-v_{0}}\right)^{s_{C}}}+s_{D}
$$

The wind conditions at various sites in Germany can be quite different from each other, which also influences the heat demand of a building. The reason behind this connection between mean wind speed and heat demand is that during ventilation a higher air exchange rate occurs if the wind velocity is higher. To consider this effect in the calculation of $h$ five different wind classes are introduced ranging from very low wind speeds to high wind speeds. So first of all the mean wind speed of one year need to be calculated by using the hourly wind data of the test reference year. Table 3 presents the four Sigmoid parameters for different wind speed classes.

Table 3: Sigmoid parameter for different wind classes $[32$

\begin{tabular}{ccccc}
\hline Wind speed class $\frac{m}{s}$ & $s_{A}$ & $s_{B}$ & $s_{C}$ & $s_{D}$ \\
\hline $0-1$ & 3.0779823254 & -37.4550564205 & 6.1084050390 & 0.1230000000 \\
$1-2$ & 2.9273090522 & -37.3533845914 & 5.8471730774 & 0.1470000000 \\
$2-3$ & 2.7941105885 & -37.1764144159 & 5.4034460226 & 0.1713913947 \\
$3-4$ & 2.6279078804 & -37.1327012568 & 5.2719372668 & 0.1950000000 \\
$>4$ & 2.4785575976 & -37.0075093695 & 4.9566020451 & 0.2190000000 \\
\hline
\end{tabular}

In the next step the daily demand value will be obtained, by using this costumer value. The temperature regression function $h$ in respect of a given daily mean temperature represents the daily variation over a year of the heat demand. So this $h$ value is multiplied by the costumer value to obtain a daily heat demand value, which is done for the whole year to obtain 365 daily demand values.

$$
Q_{D ; h e a t}=h(v) \cdot C V
$$


Moreover the VDI 4655 [33] provides a set of normalised energy demand profiles to calculate a demand value for every minute of a day. These profiles $F_{\text {heat }, n}$ are called typical day profiles and are ratios of the instantaneous energy demand over the daily energy demand, which means that the profile symbolises the percental distribution over one day. The sum of this percental distribution is always $100 \%$, but the specific values of the vector $F_{\text {heat }, n}$ vary for different types of days. These different days exist due to the fact that during workdays most of the consumption will be in the morning and the evening, while at Sundays the consumption is more equally distributed over the whole day. So the daily demand values are then multiplied by the a vector of the percental distribution of the heat demand.

$$
Q_{\text {heat }}(t)=F_{\text {heat }, n} \cdot Q_{D ; \text { heat }}
$$

By summing up these values for every hour the hourly heat demand can be calculated.

To summarise this paragraph it is possible to determine the heat demand of every hour in a year by using the method of reference demand profiles in combination with the VDI 4655. But it need to be stressed that by combining these two methods the overall heat demand of this obtained profile may be smaller then the yearly demand given in table 2 . This issue occurs due to the fact that the daily demand value is multiplied by the energy demand profiles (see equation 57. In the summer time the heat demand profile only contains zeros, as no heating is necessary if the outside temperature is above $15^{\circ} \mathrm{C}$. At the same time it could happen that the daily demand value $Q_{D \text {; heat }}$ is very small but not zero, for the simple reason that this value is calculated according to the temperature of the last three days and not according to the temperature of the precise day.

The yearly hot water and electricity demand of a detached house mostly depends on the number of people living in it. To ensure comparability of the different sites, it is assumed that two people are living in every house. VDI [33] proposes a yearly energy demand $Q_{Y \text {;water }}$ of $1000 \mathrm{kWh}$ to supply hot water and a yearly electricity demand $W_{Y}$ of $4000 \mathrm{kWh}$ for a detached house with $N_{\text {pers }}=2$. The standard also includes equations to calculate the daily energy demand for hot water $Q_{D ; \text { water }}$ and electricity $W_{D}$ (equations 6 and 7 .

$$
Q_{D ; \text { water }}=Q_{Y ; \text { water }} \cdot\left(\frac{1}{365}+N_{\text {pers }} \cdot F_{\text {water }}\right)
$$

$$
W_{D}=W_{Y} \cdot\left(\frac{1}{365}+N_{\text {pers }} \cdot F_{\text {elec }}\right)
$$

The parameter $F_{\text {elec }}$ and $F_{\text {water }}$ are given in the standard [19]. The calculated daily values are multiplied by the typical day profiles for electricity and hot water demand, as it is done above to assess the heat demand for each hour.

\subsection{House heating system}

A measure of the efficiency of a heat pump is the coefficient of performance (COP), which is defined as the ratio of heat delivered by the heat pump $Q_{H}$ and the electricity demand of the compressor $P_{\text {comp }}$.

$$
C O P=\frac{Q_{H}}{P_{\text {comp }}}
$$

To facilitate comparisons the heating capacity COP for a heat pump is given for specific conditions. An air-water heat pump that works at ambient temperature of $7{ }^{\circ} \mathrm{C}$ and aims at a flow 
Table 4: Specifications of modelled heat pump

\begin{tabular}{ccccccc}
\hline \multirow{2}{*}{ Name } & \multicolumn{2}{c}{ A7/W55 } & \multicolumn{2}{c}{ A-10/W55 } & expenditure & data \\
& COP & power & COP & power & & source \\
\hline Ochsner Eagle 717 & 3.3 & $11 \mathrm{~kW}$ & 2.3 & $14 \mathrm{~kW}$ & $20,639 €$ & {$[34]$} \\
\hline
\end{tabular}

temperature of $55{ }^{\circ} \mathrm{C}$ has the acronym A7/W55. The specifications of the chosen heat pump are given in table 4

For the hot water, a storage tank with three incoming and three outgoing connections is modelled. Two heat exchangers are needed in the tank. The first one is connected with the heat pump and enables an individual mass flow that is not influenced by the mass flow of the heating circuit. The second heat exchanger is necessary to divide the fresh hot water (hot water - HW) from the water that flows inside the heating system (heat circuit - HC). Only with a disconnection of these two water flows an adequate quality of fresh water is given. In case the heat provided by the storage is not sufficient to fulfil the needs of the house heating/hot water system each circuit includes an additional heating element to increase the temperature if necessary. Using a controler the heat pump can be operated in full time or part time load according to mass flow and temperature of the outgoing circuits. A schematic figure is given in figure 1

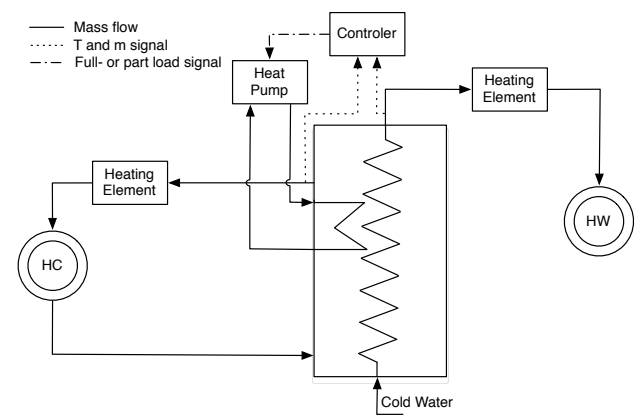

Figure 1: Schematic circuit diagram for the heating system

\subsection{Profitability calculation}

It is assumed that all houses which were built after 2002 are equipped with a condensing boiler. As these houses are not older than 20 years according to [35] investment costs for a new boiler can be neglected and only the fuel costs are considered. For evaluation of the profitability of the systems, the annuity method [35] is used. The price for the heat pump can be found in [36]. The costs for the wind turbines are shown in [20, 21], those for the PV plants are given by [22, 23, 24, 25, 26, 27, 28, 29, 30]. The investment costs of a boiler according to the living space of the house $\left(A_{\text {house }}\right)$ are specified by equation 9 [35].

$$
P a_{\text {boiler }}=2253.6 \cdot \frac{A_{\text {house }}}{A_{\text {house }}^{0.7349}}
$$


For the 1500 litre storage tank the price is defined as $1700 €$. Before the annuity of the investment is calculated, first all prices need to be set to one point in time. As all researched prices are spread in time, it is necessary to consider the inflation of the prices. All the prices are then totalised for each system (symbolised with $C_{\text {all }}$ ) to calculate the annuity of the investment.

$$
A_{\text {invest }}=C_{\text {all }} \cdot a
$$

7 The annuity factor a is determined as followed:

$$
a=\frac{(1+i)-1}{1-(1+i)^{-T}}
$$

The interest rate $\mathrm{i}$ is $4 \%$.

Before starting with this calculation of the heating cost annuity it is necessary to specify the heating system which is already existing in the house. As there are various types of heating systems implemented in detached houses all over Germany it would be unrewarding to calculate this annuity for all of these heating systems. So for the reason of a concise overview the two most common heating systems are chosen, which are gas and oil fired heating systems [37]. The annuity of the heat demand is determined by the generated heat $Q_{f u e l}$ of a given heating system and the respective fuel prices $C_{f u e l}$.

$$
A_{\text {fuel }}=Q_{\text {fuel }} \cdot C_{\text {fuel }} \cdot a \cdot b
$$

The price dynamic annuity factor $b$ expresses the issue that there will be price changes during the observation time.

$$
b=\frac{1-\left(\frac{1+r}{1+i}\right)^{T}}{(1+i)-(1+r)}
$$

The price change factor $r$ differs with the respective energy source (see table 5).

The energy effort for the heat generation $\left(Q_{f u e l}\right.$ in equation 12$)$ is not the same as the energy

Table 5: Price change factor and price for oil, gas and electricity

\begin{tabular}{cccc}
\hline Type & price change factor \%/a & expenditure cents/kWh & data source \\
\hline Oil & 6.24 & 6.73 & {$[38]$} \\
Gas & 5.06 & 7.24 & {$[38]$} \\
Electricity & 5.13 & 28.73 & {$[38,40]$} \\
\hline
\end{tabular}

which is needed to fulfil the heat demand. The reason for this is that the generation of heat is not an ideal process and some energy can not be used due to losses. To obtain the value of $Q_{\text {fuel }}$ the heat demand of the respective house type is divided by the efficiency of the heating device. This efficiency varies with the respective fuel type and is given as followed for a condensing boiler [41]:

- $102 \%$ for oil

- $105 \%$ for gas 
The annuity of the demand for electricity is calculated using the electricity costs given in table 5 The sum of these three annuities is the overall annuity. The levelized cost of electricity (LCoE) is calculated by dividing the annuity by the relevant demand (see equation 14 ). So the LCoE of the conventional system is calculated by the sum of the LCoE of the conventional heating system and the LCoE of the electricity demand. For the renewable systems the annuity of the system, containing the annuity of the capital and operational cost, is divided by the electricity demand of the house and the electricity demand for heating purposes.

$$
L C o E=\frac{A_{i}}{E_{\text {demand,i }}}
$$

Whenever a profitability analysis is performed it is important to carry out a sensitivity analysis, for the simple reason that such an analysis reveals the range of the costs. Furthermore it determines which factor is highly influencing the system and which factor is neglectable because the influence on the system is small. In this study a sensitivity analysis is conducted for the profitability analysis using the Monte Carlo method. The reason for applying a Monte Carlo instead of a standard sensitivity analyses is the benefit of varying all parameters at the same time. In the standard sensitivity analyses usually one parameter is varied while the others are kept constant. Such an analyses reveals the highly influencing parameters but does not illustrate probable future cases as the aspect of only one changing parameter is not likely. In this study the sensitivity analyses is used to present the cost range rather than identifying the most influencing factor, which is why the Monte Carlo simulation is used.

The used Monte Carlo simulation is a statistical method, in which random numbers uniformly distributed between zero and one are generated to represent the risk that a given value can vary in a distinct range. This range is fixed in the analysis to a minimum and maximum value. The reason for fixing the range is that all considered values, like the interest rate or the expenditure of a distinct component, will not change unlimited in time. All factors that are changing during the simulation and their respective ranges are shown in table 6. With the help of the aforementioned random number $N_{\text {rand,i }}$ the values $Y_{i}$ of the factors are calculated in between their ranges $\left[X_{\min , i} X_{\max , i}\right]$.

$$
Y_{i}=X_{\min , i}+N_{\text {rand }, i} *\left(X_{\max , i}-X_{\min , i}\right)
$$

In the simulation 5000 cycles are performed and in every cycle for all factors equation 15 is calculated to obtain changing values for the investment costs, the interest rate, the price change factor of oil, the price change factor of gas and the price change factor of electricity. It is necessary to emphasise that the factors are not changing in the same pattern, which means the interest rate could be very high while the price change factor of one fuel type is very low in the same cycle. This is realised by calculating an individual random number for every factor, which enables a decoupled simulation. In every cycle the whole profitability calculation, as described above, is performed with the random generated factors to estimate the probable distribution of the LCoE.

\section{Results and discussion}

The LCoE for oil or gas is between 5.1 and 5.2 cents/kWh for all regions. This reflects the pure fuel prices for fulfilling the heat demand. The electricity demand is fully fulfilled by electricity from the grid. In the paragraph below the named LCoE always include electricity and 
Table 6: Parameters for Monte Carlo simulation

\begin{tabular}{cccccc}
\hline Factor $Y_{i}$ & unit & data source & default & minimum & maximum \\
\hline interest rate & $\%$ & assumption & 4 & 2 & 6 \\
$r_{\text {oil }}$ & $\% / \mathrm{a}$ & {$[38]$} & 6.24 & -18.5 & 33.5 \\
$r_{\text {gas }}$ & $\% / \mathrm{a}$ & {$[38]$} & 5.06 & -20.8 & 33.7 \\
$r_{\text {elec }}$ & $\% / \mathrm{a}$ & {$[38]$} & 5.13 & 2.3 & 12.1 \\
investment & $\%$ & assumption & 100 & 90 & 100 \\
\hline
\end{tabular}

heat demand. In comparison, the costs for a system with a heat pump and a PV plant are above 20 cents/kWh for all plant options. There are several reasons for the higher prices. While the investment costs of the PV plant are not neglegtable, it does not influence the system costs to such level. However, the heating pump influences the system in two ways. On the one hand, the investment costs are considerable. On the other hand, especially in winter the heat demand cannot be covered by the power of the PV plant alone, but the heat pump also has to be driven by grid electricity. As the prices for this power are more than four times higher than those of gas and oil, the majority of the heat demand in the new system is covered by comparatively expensive energy.

However, there are diversions of costs between different regions. Figure 2 shows the results for the LCoE of all PV plant types in regions four (Potsdam) and five (Essen). There is a generally higher LCoE in region five, the city of Essen, compared to all other cities, lying between 24 and 26 cents/kWh. On the one hand the PV plant with the lowest nominal power is the most suitable, on the other hand this PV plant is still more expansive than the conventional system. This means that the investment costs are to high in comparison to the money saved by the generated electricity. Apparently, the cities direct solar radiation, that is $31 \mathrm{~W} / \mathrm{m}^{2}$, is not sufficient to contribute to the suggested system adequately. However, for regions with similar radiation as region five, the LCoE is still the lowest for PV plant nine. Therefore, also the distribution within the year plays an important role. For region four, the city of Potsdam, the PV plant with the highest nominal power leads to the lowest LCoE. The influence of a higher direct solar radiation is visible (yearly total $61 \mathrm{~W} / \mathrm{m}^{2}$ ). The LCoE for this configuration is between 20 and 22 cents $/ \mathrm{kWh}$. While this is more economic than the systems in other regions, it still cannot compete with the analysed fossil fuel based systems. Overall, the new systems fluctuate between 20 and 26 cents/kWh.

Generally, lower average direct radiation lead to higher LCoE, which can be attributed to the influence of the necessary grid electricity that rises and falls with the solar potential of each region. One option to counteract this is the implementation of a battery storage. Generated electricity from the PV plant can be stored and the consumption of grid power reduced. Drawbacks are not only the the current high storage prices that influence the LCoE negatively. Also, the times of high electricity demand, winter, are the ones, when there is not much solar energy to store. Therefore, a battery storage is not considered helpful for decreasing the LCoE.

The Monte Carlo analyses shows a high range of possible LCoE. Figure 3 presents the results for the lowest LCoE (Potsdam, PV system nine) and the highest one (Essen, PV system six). It is visible that the latter spreads wider. This means that the real LCoE is more likely to divert from the calculated one. However, it is also shown that even the most profitable combination of 


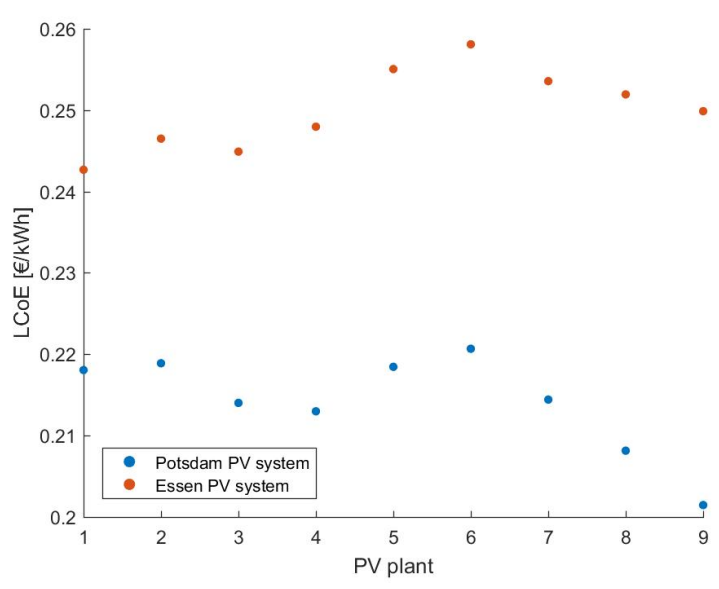

Figure 2: Comparison of LCoE of PV systems for region four and five

PV system and region is not able to undercut the costs for oil and gas in any case. Additionally, there is an increased sensitivity for higher prices. While the LCoE can be maximum 5 cents $/ \mathrm{kWh}$ lower than the base case, there is an increase up to 10 cents/kWh possible with the given assumptions for the sensitivity.

What was not considered is the influence of the PV position on the roof as well as the general building design. For this model a South-East direction of the modules was assumed. A position in South direction is positive for the capacity, while a sattle roof with tiles showing in the line of West-East might increase the LCoE even further. Also, there is the possibility of shading due to trees or chimneys. Additionally it cannot be assumed that all roofs have the capacity for a $9.9 \mathrm{~kW}$ PV plant. This shows that the analysis of a PV plant plus heat pump system is always influenced by individual factors.

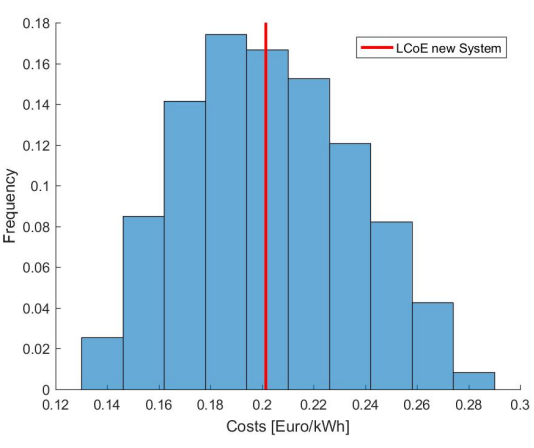

(a) PV system nine in Potsdam

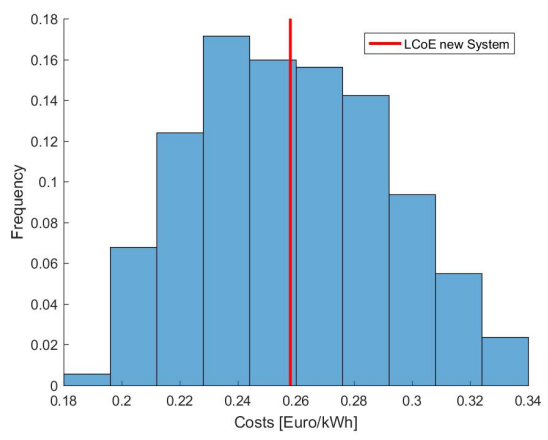

(b) PV system six in Essen

Figure 3: Results of Monte Carlo analysis for PV 
In comparison, a wind turbine system together with the same heat pump as applied to the PV system could generate for some regions prices below the conventional systems. As before, also the profitability of the renewable system highly depends on the wind resources and therefore on the location of the system. Figure 4 shows the LCoE for the different wind turbines in Bremerhaven, which was one of the best region, and in Garmisch Patenkirchen, the region with the worst wind situation. It needs to be emphasised that the turbines two, four and six can be characterised as low wind turbines as these turbines are reaching a high portion of the nominal power already at low wind speeds. Compared to wind turbines two and six the wind turbine four has higher specific cost, which is the reason why the two wind turbines two and six appear out of the trendline in a positive perspective. This is not only the case for Bremerhaven. For all regions, except for Garmisch Patenkirchen and Fichtelberg, turbine six always generates the lowest LCoE. For Garmisch Patenkirchen the LCoE are all high compared to the conventional or to the PV system.

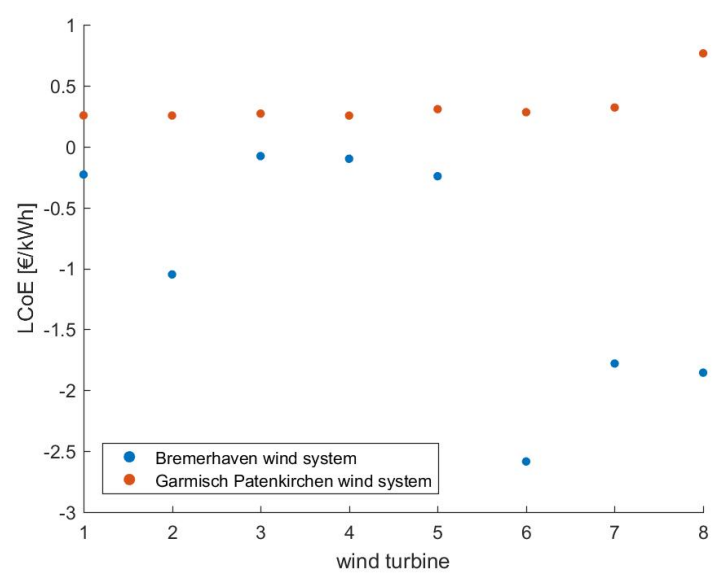

Figure 4: Comparison of LCoE of wind turbine systems for Bremerhaven and Garmisch-Patenkirchen

When the wind system is placed in a location with very good wind resources the wind turbine generates enough electricity to fulfil the electricity demand, the demand of the heat pump and on top feeds electricity into the grid. The feed in tariff is assumed with 4.56 cents $/ \mathrm{kWh}[6]$. In the case of Bremerhaven these revenues are so high that negative LCoE are generated. From the 15 analysed regions only for three regions all wind turbine systems were more expensive than the conventional systems. For all other regions there was at least one wind turbine system which was cheaper than an oil conventional system. Why are small wind turbines capable of fulfilling the demands more economically than conventional systems and PV systems not? The reason for this is the seasonal variation of the resources. In Germany the PV resources are much better in the summer than in the winter time. For the wind resources this situation is upside down, so the best wind conditions usually occurring in the winter time, where also the highes heat demand is needed.

A sensitivity analysis for the best wind turbine of each region is conducted and presented in table 7. It can be seen that the economic feasibility of such a system could be sensitive. Con- 
sidering the case of Kassel, the system is under the normal condition not competitive with the conventional systems, but under minimum condition even a negative LCoE occurs. It is important to stress that the wind data in the test reference year is originally coming from wether stations. These wether stations are usually placed in an area without big buildings, which is why nearly no wind shading effect is occurring. The surrounding of the wind turbine is relevant, for the simple reason that larger objects in the direct proximity to the wind turbine provoke turbulence and shading effects. The magnitude of the turbulence depends on the shape of the object, namely the hight and width. As the towers of small wind turbines are usually not so high the issue of the surrounding might be of greater importance for small wind applications. Especially in housing estates this could be a limiting factor.

Table 7: Monte Carlo simulation for the best wind turbine of each region

\begin{tabular}{|c|c|c|c|c|c|}
\hline Region & wind turbine & unit & $\mathrm{LCoE}$ & $L C o E_{\min }$ & $L C o E_{\max }$ \\
\hline Bremerhaven & 6 & $\frac{€}{k W h}$ & -2.58 & -2.66 & -2.49 \\
\hline Rostock & 6 & $\frac{€}{k W h}$ & -1.39 & -1.46 & -1.30 \\
\hline Hamburg & 6 & $\frac{€}{k W h}$ & -1.27 & -1.34 & -1.17 \\
\hline Potsdam & 6 & $\frac{€}{k W h}$ & -0.08 & -0.15 & 0.01 \\
\hline Essen & 6 & $\frac{€}{k W h}$ & -0.98 & -1.05 & -0.89 \\
\hline Bad Marienberg & 6 & $\frac{€}{k W h}$ & -0.35 & -0.42 & -0.27 \\
\hline Kassel & 6 & $\frac{€=}{k W h}$ & 0.13 & -0.05 & 0.21 \\
\hline Braunlage & 6 & $\frac{€}{k W h}$ & -0.19 & -0.25 & -0.10 \\
\hline Chemnitz & 6 & $\frac{€}{k W h}$ & -1.63 & -1.70 & -1.54 \\
\hline Hof & 6 & $\frac{€}{k W h}$ & -0.18 & -0.24 & -0.09 \\
\hline Fichtelberg & 8 & $\frac{€}{k W h}$ & -4.91 & -4.98 & -4.83 \\
\hline Mannheim & 6 & $\frac{€}{k W h}$ & 0.17 & -0.09 & 0.26 \\
\hline Muehldorf & 6 & $\frac{€}{k W h}$ & -0.29 & -0.36 & -0.20 \\
\hline Stoetten & 6 & $\frac{€}{k W h}$ & -2.05 & -2.12 & -1.96 \\
\hline Garmisch Patenkirchen & 4 & $\frac{€}{k W h}$ & 0.25 & 0.19 & 0.33 \\
\hline
\end{tabular}

One major aspect that influences the results is the price for the heat pump. As most heat pumps are configured for room heating purposes, their optimum lies at a flow temperature of $35{ }^{\circ} \mathrm{C}$. This temperature is not sufficient to generate hot water. The simulated heat pump was chosen because the COP at A7/W55 is 3.3 and therefore comparatively high. However, the investment costs are up to double of those for other kind of heat pumps. This inflates the total costs. Choosing another heat pump might reduce the costs at the expense of the COP. Another option is to set the flow temperature at $35^{\circ} \mathrm{C}$ and use direct heating to get to the necessary hot water temperature. As the needed energy for room heating is more than ten times higher than the one for hot water, the system should be configured more to optimise the former trading off the efficiency of the latter. 
Another aspect is that there is a decrease in heat demand for newer buildings, enforced by regulations on the maximum primary energy demand that is allowed in newly constructed buildings. This means that for these kind of buildings the total heat demand is lower but also the diversion in demand between summer and winter is reduced. This means that the VDI standard used in this study might not be applicable for newer buildings and the results for both technologies, but especially for PV could be more favourable.

Oil and gas as an energy source has both a highly volatile price and a high price change factor, which, in a poor constellation, could provoke very high annuities by considering 20 years of operation. Moreover the oil or gas reference system depends on two energy sources, namely oil or gas on the one hand and electricity on the other hand. Therefore, the oil or gas system is more economical according to the given calculation but there is some uncertainty. Also, it is not taken into account that in future subsidies might decrease investment costs for the heat pump. Schemes for building modernisation are already in place. This will decrease the heat demand and thereby decrease the influence of this sector compared to the power sector.

The climate change is also of relevance. The reference model by [19] additionally gives the expected climate data for a synthesised year in the time frame 2021 to 2035 . This data shows an increase in direct radiation by around $10 \%$. This will influence the capacity of PV plants positively. Together with the increase in average temperature, that is also forecasted, and a resulting decrease in heat demand, this might affect the efficiency of PV-based heating systems. Especially in regions that are already windy the wind speed is forecasted to increase in future, while a region as Garmisch-Patenkirchen will remain a windless area. Therefore, mainly regions that already profit from wind at the moment will be affected positively. Finally, it has to be empathised that other aspects are relevant for putting the model into reality, e.g. the question of space and land use to build up a small wind turbine.

\section{Conclusion}

The case study shows that at the moment small wind turbines are a feasible option for cover the energy demand of a detached house with an integrated heat pump in many German regions, mainly those with high wind resources. In a lot of cases even an overproduction of electricty can be achieved leading to negative LCoE. However, the high sensitivity of this systems needs to be considered. It can be shown that low wind turbines improve the system efficiency. However, for some regions, e.g. Garmisch-Patenkirchen, the LCoE is 0.25 cents $/ \mathrm{kWh}$, which is around five time higher than the one of an oil or gas system. Even considering the sensitivity of the results, it is clear that in those regions small wind turbines are not favourable.

PV plants are not suitable at the moment for the heat demand coverage as the specific costs outgo the ones for oils and gas by far. Even in the best case, the city of Potsdam, the LCoE is 22 cents/kWh, four times higher than a conventional system. While the sensitivity analysis shows that numbers as low as 14 cents $/ \mathrm{kWh}$ are possible, it is still not sufficient to be a competition in the economical point of view. Modifications might increase the economic efficiency of PV based systems, e.g. lower flow temperatures. However, this is only applicable if building isolation improves. For older buildings this means that modernisation needs to be done on such extensive level that their efficiency standard compares to the one of recently constructed houses. 
It needs to be emphasised that maybe there are more suitable devices available on the market, which were not analysed for the simple reason that exact data for these devices were not obtainable. This insufficient data in combination with the enormous number of available devices may reduce the willing to invest in such systems, as the engineering effort is higher then choosing an oil or gas system.

In general it was demonstrated that for some sites an implementation of a wind system is profitable. This shows the ability of small wind turbine applications to contribute to cover the heat and electricity demand of houses, without using conventional energy sources. On the one hand this enables the owner of the house to generate a given share of the electricity consumption by himself and therefore life partly autarchic. On the other hand such a system improves the security of supply as the house no longer depends on two energy sources. Especially the prices of oil and gas are highly volatile and additionally depending on the political situation. Another important issue which was not addressed in the analysis but a motivation of this study is the ecological benefit of such a system. Considering the recent discussions on $\mathrm{CO}_{2}$ pricing this ecological aspect could correlate with economic ones in the near future. This will have further influence on the cost comparison of renewable energy systems compared to fossil ones.

The model will be used to look into the relevance of wind and solar based renewable energy sources to cover local energy demands in future climate scenarios. Furthermore, research will be done on other house age groups, older as well as very new ones and especially passive houses.

\section{References}

[1] Bundesministerium für Umwelt, Naturschutz und nukleare Sicherheit Klimaschutzplan 2050 - Klimaschutzpolitische Grundsätze und Ziele der Bundesregierung. Berlin, Germany 2016

[12] Umweltbundesamt Erneuerbare Energien in Zahlen. Available at: umweltbundesamt.de/themen/ klima-energie/erneuerbare-energien/erneuerbare-energien-in-zahlen [accessed 24.2.2019].

[3] Schmitz J., Volkmann B. Ihr Photovoltaik-Ratgeber. Available at: pv-installation.com/downloads/ Photovoltaik-Ratgeber.pdf [accessed 24.2.2019].

[4] Ibrahim H., Ilinca A., Perron J. Energy storage systems? Characteristics and comparisons. Renewable and Sustainable Energy Reviews 2008;12(5):1221 - 1250.

[5] Arteconi A., Hewitt N., Polonara F. Domestic demand-side management(DSM): Role of heat pumps and thermal energy storage (TES) systems. Applied Thermal Engineering 2013;51(1-2):155?165.

[6] Bundesnetzagentur EEG-Registerdaten und -Fördersätze. Available at: bundesnetzagentur.de/ DE/Sachgebiete/ElektrizitaetundGas/Unternehmen_Institutionen/ErneuerbareEnergien/ ZahlenDatenInformationen/EEG_Registerdaten/EEG_Registerdaten_node.html [accessed 24.2.2019].

[7] Statistisches Bundesamt Preise, Daten zur Energiepreisentwicklung - Lange Reihen von Januar 2005 bis Dezember 2018. Wiesbaden, Germany: 2019.

[8] Costs seasonal storage Available at: http://www.saisonalspeicher.de/Planung/Voraussetzungen/ Kosten/tabid/87/Default .aspx [accessed 25.5.2020].

[9] Mean building age in Germany Available at: https://de.statista.com/statistik/daten/studie/ 37303/umfrage/entwicklung-des-durchschnittsalters-von-gebaeuden-seit-1991/ [accessed 25.5.2020].

[10] Deschermeier P., Henger R., Seipelt B., Voigtländer M. Wohnungsmangel in den Städten, Leerstand auf dem Land. Cologne, Germany: Institut der deutschen Wirtschaft (IW); 2017 IW-Kurzbericht No.: 44.2017.

[11] Umweltbundesamt Energieverbrauch privater Haushalte. Available at: https://www.umweltbundesamt. de/daten/private-haushalte-konsum/wohnen/energieverbrauch-privater-haushalte [accessed 24.2.2019]. 
[12] Enteria N., Yoshino H., Satake A., Takaki R.,Ishihara H., Baba S. Benefits of utilizing on-site and off-site renewable energy sources for the single family detached house. International Journal of Energy and Environmental Engineering 2016;7(2):145-166.

[13] Ghaith A., Epplina F., Frazier R. Economics of household wind turbine grid-tied systems for five wind resource levels and alternative grid pricing rates. Renewable Energy 2017;109:155-167.

[14] Predescu M. Economic evaluation of small wind turbines and hybridsystems for residential use. Renewable Energy and Environmental Sustainability 2016;1(33):1-6.

[15] Grieser B., Sunakb Y., Madlener R. Economics of small wind turbines in urban settings: An empirical investigation for Germany. Renewable Energy 2015;78:334 - 350.

[16] Bracke J., Tomaschek J., Brodecki L., Fahl U. Techno-ökonomische Bewertung von Energie-Autarkie für die Energieversorgung von Einfamilienhäusern. Zeitschrift für Energiewirtschaft 2016;40(3):127-137.

[17] Merkel E., Kunze R., McKenna R., Fichtner W. Modellgestützte Bewertung des Kraft-Wärme-Kopplungsgesetzes 2016 anhand ausgewählter Anwendungsfälle in Wohngebäuden. Zeitschrift für Energiewirtschaft 2017;41(1):1-22.

[18] Kranzl L., Müller A., Maia I., Büchele R. Wärmewende 2030: Analyse der Erfordernisse und Konsequenzen: Teilbericht zur Wirtschaftlichkeitsanalyse von Heizsystemen. Vienna, Austria: 2017 Nov.

[19] Deutscher Wetterdienst Testreferenzjahre von Deutschland für mittlere und extreme Witterungsverhältnisse TRY. Offenbach, Germany: Selbstverlag Deutscher Wetterdienst; 2012

[20] Simic Z., Havelka J., Vrhovcak M. Small wind turbines - A unique segment of the wind power market. Renewable Energy 2013; 50: 1027-1036.

[21] Bortolini M., Gamber M., Graziani A., Manzini R., Pilati F. Performance and viability analysis of small wind turbines in the European Union. Renewable Energy 2014; 62: 629-639.

[22] Aleo Solar S19 HE Tec $2.44 \mathrm{~kW}$. Available at: photovoltaik4all.de/solarpaket-s-2, 4-kwp-aleo-solar-komplettanlage [accessed 25.2.2019].

[23] Viessmann Vitovolt 300 Typ P275 AB $3.3 \mathrm{~kW}$. Available at: photovoltaik4all.de/komplettanlagen/ fuer-satteldach/1197/solarpaket-s-3-kwp-viessmann-photovoltaikanlage [accessed 25.2.2019].

[24] Viessmann Vitovolt 300 Typ P275 AB $4.4 \mathrm{~kW}$. Available at: photovoltaik4all.de/komplettanlagen/ fuer-satteldach/1198/solarpaket-m-4-kwp-viessmann-photovoltaikanlage [accessed 25.2.2019].

[25] Aleo Solar X59 HE Tec $5.58 \mathrm{~kW}$. Available at: photovoltaik4all.de/solarpaket-1-5, 4-kwp-aleo-solar-komplettanlage [accessed 25.2.2019].

[26] LG325N1K-V5 NeON 2 Black Cello 5.85. Available at: photovoltaik4all.de/ 6-kwp-lg325n1k-v5-neon-2-black-cello-325-wp-sma-photovoltaikanlage [accessed 25.2.2019].

[27] BenQ Solar SunForte PM096B00 $6 \mathrm{~kW}$. Available at: photovoltaik4all.de/komplettanlagen/ fuer-satteldach/3236/6-kwp-benq-solar-sunforte-pm096b00-335-wp-photovoltaikanlage [accessed 25.2.2019].

[28] LG320N1K-V5 NeON 2 Black Cello $6.72 \mathrm{~kW}$. Available at: photovoltaik4all.de/6, 720-kwp-lg320n1k-a5-neon-2-black-cello-320-wp-sma-photovoltaikanlage [accessed 25.2.2019].

[29] Aleo Solar X79 8.37 kW. Available at: photovoltaik4all.de/solarpaket-xl-8-kwp-aleo-solar-komplettanlage [accessed 25.2.2019].

[30] LG330N1C-A5 NeON $29.9 \mathrm{~kW}$ Available at: photovoltaik4all.de/komplettanlagen/fuer-satteldach/ 9-9-kwp-pv-anlage [accessed 25.2.2019].

[31] Loga T., Diefenbach N., Born R. Deutsche Gebäudetypologie - Beispielhafte Maßnahmen zur Verbesserung der Energieeffizienze von typischen Wohngebäuden. Darmstadt, Germany: Institut Wohnen und Umwelt; 2011

[32] Bundesverband der deutschen Gas- und Wasserwirtschaft Anwendung von Standardlastprofilen zur Belieferung nicht-leistungsgemessener Kunden. Wirtschafts- und Verlagsgesellschaft Gas und Wasser mbH; 2006

[33] VDI-Fachbereich Energietechnik Referenzlastprofile von Ein- und Mehrfamilien-häusern für den Einsatz von KWK-Anlagen. VDI-Gesellschaft Energie und Umwelt; 2008

[34] Prüfresultate Luft/Wasser-Wärmepumpen basierend auf der EN 14511:2013/EN 14511:2018 und EN 14825:2013/EN 14825:2016. Available at: ntb.ch/fileadmin/NTB_Institute/IES/pdf/Projekte_WPZ/ PruefResLW180810.pdf [accessed 25.2.2019].

[35] VDI-Fachbereich Technische Gebäudeausrüstung Wirtschaftlichkeit gebäudetechnischer Anlagen - Grundlagen und Kostenberechnung. VDI-Gesellschaft Bauen und Gebäudetechnik; 2012

[36] sanitaerprofi.at/Ochsner/OCHSNER-AIR-717-C-EAGLE-285640::9498516.html [accessed 25.2.2019].

[37] Statistisches Bundesamt Wirtschaftsrechnungen - Einkommens- und Verbrauchsstichprobe Wohnverhältnisse privater Haushalte. Wiesbaden, Germany: 2015

[38] Statistisches Bundesamt Preise, Daten zur Energiepreisentwicklung -Lange Reihen von Januar 2000 bis Mai 2014. Wiesbaden, Germany: 2014

[39] Statistisches Bundesamt Index der Erzeugerpreise gewerblicher Produkte (Inlandsabsatz) nach dem Güterverzeichnis für Produktionsstatistiken, Ausgabe 2009. Wiesbaden, Germany: 2014

[40] Bundesverband der Energie- und Wasserwirtschaft e.V. BDEW-Strompreisanalyse Mai 2013 - Haushalte und In- 
530 dustrie. Berlin, Germany: 2013

531 [41] Schmid C. Energieeffizienz in Unternehmen - Eine wissensbasierte Analysis von Einflussfaktoren und InstrumentenZürich, Switzerland: vdf Hochschulverlag; 2004 